\title{
The Basic Course and Overview of Rural Ethics Research in the Past 70 Years since the Founding of New China
}

\author{
Ang Liu $^{1,2}$, Yi Yang ${ }^{3 *}$ \\ ${ }^{1}$ School of Marxism Studies, Nanjing Normal University, Nanjing, People's Republic of China \\ ${ }^{2}$ Nanjing Normal University Rural Culture Promotion Research Center, Nanjing, People's Republic of China \\ ${ }^{3}$ College of Food Science and Engineering, Nanjing University of Finance and Economics, Nanjing, People's Republic \\ of China \\ E-mail: mowxyy@163.com
}

\begin{abstract}
Rural is the foundation of Chinese society. The state of rural development will directly affect the overall development of the country. Since the founding of the People's Republic of China, the discussion of the rural has been appeared frequently. There were many studies involving village moral relations and ethical order. Generally speaking, China's rural ethics research went through three stages on the whole, resuscitation and exploring stage (the beginning of the founding), budding period stage (after the reform and opening up) and rapid development stage (since the new century).
\end{abstract}

Keywords: New China, rural country, ethics research.

\section{Introduction}

The report of the 19th National Congress of the Communist Party of China puts forward the implementation of rural revitalization strategy. It was the first time that the Party Central Committee raised the rural issues into the strategic issues. It also put the rural revitalization and regional coordinated development and healthy China as the strategy of national development. Since the founding of New China in 1949, China's rural areas had attracted the attention of people at home and abroad. There was consideration about the relationship between rural social ethics in many of the research. After the reform and opening up, there were many discussions on the rural social morality, the village cultural structure and the villagers' moral psychology and other issues. It further promoted the germination of rural ethics research. Since the new century, rural ethics research had entered a stage of rapid development. It produced growing research results, further expanded team and more diversified research methods.

\section{The Exploration Period of Rural Ethics Research (1949-1978)}

At the beginning of the founding of New China in 1949, the countryside was in ruins. The study of the villages was in full swing. The rural research mainly focused on historical events such as agrarian reform, agricultural cooperation and people's commune in this period. Although rare interpretations of rural ethics were made, whether the formulation of relevant policies or the history of daily life of villagers Thinking, to a certain extent, it involved the exploration of rural ethics.

The 'Agrarian Reform Law of the People's Republic of China' was promulgated in 1950. It clearly stipulated the abolition of land ownership in the feudal exploitation of the landlord class and the implementation of farmers' land ownership.[1]It completely destroyed the feudal land ownership of more than 2,000 years in our country and satisfied the moral and psychological appeal of the peasants 'the cultivators have their fields'. Along with the process of land reform, the state has promulgated the 'Resolution of the Central Committee of the Communist Party of China on Mutual Assistance in Agricultural Production' and the 'Resolution of the Central Committee of the Communist Party of China on the Development of Agricultural Cooperatives' in order to promote mutual cooperation among farmers, improve labor efficiency and reduce operational risks. In a certain sense, it promotes the production ethics relationship of rural cooperation and win-win. On the basis of the continuous deepening of agricultural cooperation, the people's communes began to emerge. At the end of August 1958, the enlarged meeting of the Political Bureau of the Central Committee officially adopted the 'Resolution of the Central 
Committee of the Communist Party of China on the Establishment of People's Communes in Rural Areas'. It further promoted the people's communes to the rural areas of the country. In explaining the 'people's commune is an inevitable trend of the development of the situation', the resolution pointed out that 'public canteens, kindergartens, nurseries, sewing groups, hairdressing rooms, public baths, happy homes, agricultural middle schools, red schools, etc. They leaded peasants to a happier collective life, further cultivating and trained the patriotism of the peasant masses.' [2] It embodied the concern of the national policy on the spiritual life and moral level of the peasants. Regrettably, in the later development process, the people's communes violated the objective laws of the development of things, suppressed the enthusiasm of farmers' production, neglected the peasants' moral demands. This has hindered the development of villages and the formation of good ethical relations in the countryside. This evolutionary path of the people's commune has stimulated the peasants' longing for good ethical relations and laid the foundation for the germination of rural ethics.

At the same time, researchers in this period also explored the status of rural moral culture and their ethical relations from their respective perspectives. Yu Wang pointed out in the 'How to Develop Rural Recreational Movements' (1950) that 'after the peasants get the land, they first demand 'production mutual assistance, labor and family'. Then they were eager to ask for culture, health, school, and entertainment.'[3] It emphasized the urgent need for ethical culture by peasants after liberation. Zongling Shen emphasized in 'The Relationship between Law and Morality in China's Transitional Society' (1956) that 'after the completion of the task of socialist transformation, in terms of their economy and class status, they were already socialist collective farmers. But Social consciousness was lagging behind the existence of society. Therefore, in terms of its ideology, it still retained a large number of individual producers' ideas. This required the party and the state to continuously strengthen their education. The exertion of advanced social consciousness can contribute to the development of socialist transformation.' [4] It affirmed the important role of education in raising the ideology and morality of farmers. Xiaotong Fei analyzed the problems of rural cooperativeization from the perspective of economic rationality in 'Revisiting Jiangcun' (1957). He believed that while developing agriculture, the role of sideline industry and industry should not be neglected. They promoted the exploration of issues such as rural production ethics and distribution ethics.

\section{The Budding Period of Rural Ethics Research (1979-2000)}

China's reform and opening up originated in the countryside. The ethical research on the villages sprouted with the reform and opening up. The study of rural ethics in this period was mainly carried out in two aspects. On the one hand, there were a number of pioneering achievements specifically for the study of rural moral conditions. On the other hand, many national institutions related to rural research were born.

Under the promotion of reform and opening up, the level of rural economic development has been significantly improved. The ethical and cultural status of peasants has changed. Based on this situation, many scholars have focused their research on the countryside. They studied the ethical relationship of the village and the changes in the moral development of the villagers. For example, in 1983, Fu'en Zhu published the 'Changes in the Morality of Rural Cadres Caused by the Joint Contract System'. In 1985, Zongzhi Huang published 'The Economic and Social Changes of Small Farmers in North China'. In 1986, Zhonggen Yang published 'The Performance and Tendency of Current Rural Moral Conflicts'. In 1987, Zhensheng Chen published 'Strengthening the Professional Ethics Construction of Rural Supply and Marketing Cooperatives'. Yulin Zhang and Yongming Zhang published 'New Changes in the Ethics of Rural Youth' in 1989. Huning Wang published 'Contemporary Chinese Village Family Culture: An Exploration of China's Social Modernization' in 1991. Xiaoyi Wang published 'Blood and Geography' in 1993. Shouqi Liu published 'Investigation on the Moral Development of Children Aged 3-9 in Rural Areas' in 1994. Xuanwen E published 'Systematic Engineering of Focusing on Building the Ideological and Moral System of Peasants' in 1995. Leyuan Zang and others published 'Introduction to Contemporary Chinese Rural Morals' in 1996. Hui Qin and Wen Su published 'Imperial Poetry and Rhapsody: Guanzhong Model and the Pre-modern Society revise' in 1996. Suping Huang published 'Ethics and Morality and Control of Juvenile Delinquency in Rural Areas' in 1996. Mingming Wang published 'Culture and Power in the Vision of Villages' in 1997. Zhehang Li and Lina Zhang published 'I Thoughts on the Construction of Rural Ideology and Morality' in 1997. Xiaohong Zhou published 'Tradition and Change:Social Psychology 
of Peasants in Jiangsu and Zhejiang Provinces and Their Transmutation in Modern Times' in 1998. Farong Qiao and Lihua Zhang published 'A New Topic of Moral Construction: Guiding Rural Collectivism Education with 'Two Leaps"' in 1998. Hong Wang published 'On the Relationship between Rural Moral Culture and Stable Development' in 1998. Peng Wang published 'Problems and Countermeasures for Rural Ideological and Moral Construction in the New Period' in 1999. Yunxiang Qi published 'The Flow of Gifts' in 2000. These were the fruits of this period.

In addition, many institutions related to rural ethics research during this period were approved by the Ministry of Education's Humanities and Social Sciences Key Research Base, which further promoted the germination of rural ethics research. Firstly, the Research Center for Ethics and Morality of Renmin University of China was established in 1999. The center was based on the study of the basic theory of ethics. It focused on the practical application research of contemporary social moral construction and payed attention to the hot issues of academic frontiers. It continues to introduce innovative research results, which provides a solid ethical theoretical support for rural ethics research. Secondly, the China Rural Research Center of Huazhong Normal University (renamed Huazhong Normal University China Rural Research Institute in 2011) was based on the political science discipline of Central China Normal University. It was a national comprehensive research institution on rural issues. The establishment of the research institute can carry out a multi-view comprehensive analysis of the political and ethical issues encountered in the process of rural development. Thirdly, the Research Center for Agricultural Modernization and Rural Development of Zhejiang University and the China Rural Development Research Institute of Zhejiang University were based on the agricultural economics discipline of Zhejiang University. It is an interdisciplinary open research institution that can further promote the germination of rural economic ethics research. Fourth, the study of moral education in Nanjing Normal University was based on the discipline of education in Nanjing Normal University. It mainly researched the issue of contemporary moral education, explored the direction of China's moral education, created life moral educationand provided the spirit of social ethics. It supported the study of rural moral education. In general, these national research institutions have promoted the germination of rural ethics research from the aspects of economy, politics, culture and education.

\section{The Rapid Development of Rural Ethics Research (2001-Present)}

Since the new century, the rural research under the ethical perspective has continued to develop in the depth direction. It promoted the study of rural ethics into a period of rapid development.

First of all, the study of the study of rural ethics has begun to emerge. It further clarified the concept of rural ethics research. Based on 'Local Ethics: An Interdisciplinary Perspective on 'Local Moral Knowledge' (2008) and 'New Rural Ethics: Research on Chinese Rural Ethical Issues in Social Transformation' (2016), Lulu Wang wrote 'The Outline of Chinese Rural Ethics Research' (2017). It pointed out that 'the systematic study of rural ethics in China should focus on rural family ethics, economic ethics, ecological ethics and governance ethics. It should focus on the traditional characteristics, historical changes and modern transformation of Chinese rural ethics, clarify the Chinese traditional rural ethics and modern rural ethics and grasp the historical context and general law of the development of rural ethics in China.' [5] It points the way for Chinese rural ethics research. In addition, many of the discourses of this period revolved around the connotation and extension of rural ethics, which further promoted the development of rural ethics research. For example, Bulou Li's 'Rural Moral Construction in the Period of System Transformation' (2003), Jianrong Liu's 'Research on Rural Moral Construction in the New Period' (2004), Jianping Zeng's 'Environmental Justice and Harmonious Society in Rural Perspectives' (2005), Yin Chen's 'Reform and Enhance the Ethics of Small Farmers'(2006), Jianhua Li and Bin Xing's 'Critical Ethical Dilemmas in China's Rural Grassroots Autonomy' (2009), Shuqin Wang and Dingxin Liu's 'Research on the Construction Mechanism of New Rural Social Morality' (2010), Wei Zhao's 'Regional Ethics: The Home and the Country in the Traditional Perspective'(2011), Mingjian Li's 'The Resource Significance of the Popular Education Thought of Yan Yangchu on Rural Moral Construction' (2014), Junren Wan's 'This is China in Rural Ethics'(2017), Mengqin Cao's 'Philosophical Reflections on the Construction of Environmental Ethics in China' (2017), Zhixiang Li's 'The Rational Expansion, Difficulties and Outlets of Chinese Farmers in the Process of Modernization' (2017), Yan Zhang's 'The Depression and Transformation of Traditional Rural Ethics Culture: Based on the Perspective of Rural 
Governance'(2017), ChunchenSun's 'Changes in Rural Moral Life in the 40 Years of Reform and Opening up' (2018), Guimei Li and Cuilian Zhang's 'Research on Rural Family Ethics in the 40 Years of Reform and Opening up: Background, Vision and Direction'(2018), Jianhua He's 'Country Culture" Moral Governance Function'(2018), Wugen Liu's 'Review and Prospect of China's Agricultural Ethics Research'(2018), Wei Li's 'Ethical Dimension of China's Rural Revitalization Strategy' (2018).

Secondly, the project research on the issues related to rural ethics has gradually increased. The research team of rural ethics has been expanding. We can take the National Philosophy and Social Science Fund Project as an example. In recent years, the youth projects on the study of rural ethics mainly include 'Image of South of Jiangsu in Rural Economic Ethics: An Interdisciplinary Perspective on 'Village Moral Knowledge' (2007) and 'Research on the Changes and Reconstruction of Rural Ethics since Reform and Opening up' (2013). The general projects on the study of rural ethics mainly include 'The Moral Construction of Chinese Peasants in the New Century'(2003), 'Research on Ethical and Moral Issues in the Construction of New Countryside in Ethnic Minority Areas of China' (2008), 'Research on Rural Ethics Changes and the Development of Local Novels in the Past Twenty Years' (2011), 'Ethical Issues in Rural Social Security System' (2013), 'Study on Traditional Ethics of Ethnic Minorities in Borderland and Rural Social Governance'(2015), 'Research on the Ethical Path of Rural Social Governance'(2016), 'Research on the Reconstruction of Rural Ethical Order in the Period of Contemporary Chinese Social Transformation'(2017), 'The Theoretical Connotation of Rural Ethical Construction of Socialism with Chinese Characteristics in the New Era'(2018). The key project on the study of rural ethics was 'Study on Chinese Rural Ethical Issues in the Period of Social Transformation' (2011). A major project on the study of rural ethics was "Chinese Rural Ethics Research" (2015). The smooth development of the project was inseparable from the support of the research team. The expansion of the research team further promoted the research of the subject. In this process, the research on rural ethics has developed rapidly.

Finally, diversified research methods promoted the rapid development of rural ethics research. Firstly, the interdisciplinary perspective (interdisciplinary perspective) research method solidified the theoretical basis of rural ethics research. The rural complex with "natural, social and economic characteristics has multiple functions of production, life, ecology and culture. He can promote mutual progress and symbiosis with the towns, and together constitute the main space for human activities'. [6] Ethical research on it involves not only philosophical knowledge, but also certain subject knowledge in economics, political science, and sociology. Based on this, interdisciplinary research methods can facilitate the in-depth development of rural ethics research. Secondly, text analysis is a good academic information platform for rural ethics research. Through a systematic review of the rural research texts, it is possible to have a more comprehensive understanding of the current state of rural ethics research. It can provid more targeted guidance for follow-up research. Thirdly, the empirical research method enhances the authenticity and reliability of rural ethics research. There are different 'local moral knowledge' in different villages. The study of rural ethics can only understand the ethical relationship and morality of the village more realistically based on the actual situation of the village. Then we will get valid research conclusions.

\section{Conclusion}

Generally speaking, rural ethical issues have attracted the attention of scholars during the period from the founding of New China to the reform and opening up. However, most of the research results are scattered in sociology, economics, political science and other disciplines. Ethical research is still in its infancy. After the reform and opening up, targeted research on rural moral conditions and villagers' moral emotions, as well as state-level scientific research institutions related to rural moral development emerged. This alleviated the dilemma of the previous research results and the lack of research teams. It promoted the development of rural ethics research and prompted the study of rural ethics in China to begin to sprout. Since the new century, the achievements, projects, and methods of rural ethics research have become more and more abundant, which has further accelerated the process of rural ethics research in China.

Acknowledgements. Funding for this work was provided through the Project of Philosophy and Social Science Research in Colleges and Universities in Jiangsu Province (Project No. 2019SJB072), the National philosophy and social science foundation (Project No. 15ZDB014), the Jiangsu Province Social science foundation youth program (Project No. 18ZXC003), Key research base of philosophy and social science in 
universities in Jiangsu Province: Rural culture revitalization research center (Project No.2018ZDJD-A005).

\section{References}

1. The Land Reform Law of the People's Republic of China. Selected Works of Important Documents since the Founding of the People's Republic of China, Volumes 1. Central Literature Publishing House: Beijing. 1992, page 336.

2. The Land Reform Law of the People's Republic of China. Selected Works of Important Documents since the Founding of the People's Republic of China, Volumes 11. Central Literature Publishing House: Beijing. 1995, page 446-447.

3. Yu Wang. How to Develop Rural Recreational Sports. Xinhua Bookstore East China Branch: Shanghai. 1950, page 1 .

4. Zongling Shen. The Relationship between Law and Morality in China's Transitional Society. Journal of Peking University (Humanities Science). 1956, 3.

5. Lulu Wang. The Outline of Chinese Rural Ethics Research. Journal of Social Science of Hunan Normal University. 2017, 3 .

6. Strategic Planning for Rural Revitalization (2018-2022). People's Publishing House: Beijing. 2018, page 3. 